\title{
SOCIAL CONSEQUENCES OF THE PANDEMIC IN THE CONTEXT OF MODERN EDUCATION PROBLEMS
}

\author{
Evgeniy A. Matvienko \\ Volgograd Academy of Ministry of Internal Affairs of Russia, Volgograd, Russian Federation; \\ Volgograd State University, Volgograd, Russian Federation
}

\begin{abstract}
The article is dedicated to the analysis of the main trends of evolution of the educational sphere of society and the impact of the COVID-19 pandemic on it. There are four basic trends in the development of education. The first is the audiovisual turn in modern culture accompanied by a crisis of "book culture". New learning technologies, making the material extremely accessible, do not developing the basic cognitive abilities of the individual. The "will to know" is not formed», as well as the desire and willingness to overcome the inevitable difficulties that arise in its course. The next factor is the total commercialization and consumerization of educational activities. Education is increasingly understood not as a selfless transfer of the accumulated experience of civilization, but as the provision of paid services. This gives its consumer additional rights and it creates unreasonable expectations. The third circumstance is devaluation of the classical interpretation of education as a unity of teaching and upbringing. There was a clear bias towards the first one. Education, understood as the process of forming a harmonious personality, it was in the background. The final trend in the development of education is the spreading of postmodern theories and related practices into it («postmodernization»). The pandemic is proving to be the most important factor in accelerating it. Due to the distance learning format the educational space is fragmented, atomized - both physically and intellectually. Its universal principles, goals, and content are being eroded. The social experiment launched by the pandemic proved that mostly distance education is technically possible, economically profitable, increases the emphasis on the pragmatic component of education to the detriment of the axiological one and contributes to the progressive postmodernization of education. In conclusion, it is pointed out that Western philosophy in the works of its most prominent representatives repeatedly played with the metaphor of death of God (Nietzsche), subject (Foucault), author (Barthes). By analogy, the thesis is put forward (accelerated witch pandemic) about «the death of a Teacher», manifested primarily in loss by the pedagogical community and society as a whole a view of the importance of the Teacher's social mission.
\end{abstract}

Key words: COVID-19 pandemic, education, commercialization, education, postmodernism, "death of a Teacher".

Citation. Matvienko E.A. Social Consequences of the Pandemic in the Context of Modern Education Problems. Logos et Praxis, 2021, vol. 20, no. 2, pp. 74-82. (in Russian). DOI: https://doi.org/10.15688/lp.jvolsu.2021.2.9

УДК 1:37:616-036.21

ББК 87.62

\section{СОЦИАЛЬНЫЕ ПОСЛЕДСТВИЯ ПАНДЕМИИ В КОНТЕКСТЕ ПРОБЛЕМ СОВРЕМЕННОГО ОБРАЗОВАНИЯ}

\author{
Евгений Алексеевич Матвиенко \\ Волгоградская академия МВД России, г. Волгоград, Российская Федерация; \\ Волгоградский государственный университет, г. Волгоград, Российская Федерация
}

Аннотация. Статья посвящена анализу основных современных тенденций эволюции образовательной сферы общества и влиянию на нее пандемии COVID-19. Указанные тенденции имеют собственные глубинные причины, вызревавшие в течение длительного времени. Пандемия лишь ускорила их наступление. Выделяются четыре базовых тренда развития образования. Первый из них - аудиовизуальный поворот в современной культуре, сопровождающийся кризисом «культуры книжной». Новые технологии обучения, делая материал предельно доступным, не развивают базовые познавательные способности личности. Не форми- 
руется «воля к познанию», стремление и готовность преодолевать возникающие в его ходе неизбежные трудности. Следующий фактор - тотальная коммерциализация и консьюмеризация образовательной деятельности. Образование все чаще понимается не как бескорыстная передача накопленного цивилизацией опыта, но как оказание возмездной услуги, что дает ее потребителю дополнительные права и порождает необоснованные ожидания. Третье обстоятельство заключается в девальвации классической трактовки образования как единства обучения и воспитания. Произошел явный перекос в сторону первого. Воспитание, понимаемое как процесс формирования гармоничной личности, оказалось на заднем плане. Завершающим трендом в развитии образования выступает проникновение в него постмодернистских теорий и связанных с ними практик («постмодернизация»). Пандемия оказывается важнейшим фактором ее ускорения. Вследствие дистанционного формата обучения образовательное пространство дробится, атомизируется - как в физическом, так и в интеллектуальном плане. Размываются его универсальные принципы, цели и содержание. Запущенный пандемией социальный эксперимент доказал, что преимущественно дистанционное образование возможно технически, выгодно экономически, усиливает акцент на прагматический компонент образования в ущерб аксиологическому и способствует прогрессирующей постмодернизации образования. В заключение указывается, что западная философия в работах виднейших своих представителей неоднократно обыгрывала метафору смерти Бога (Ницше), субъекта (Фуко), автора (Барт). По аналогии выдвигается тезис об (ускоренной пандемией) «смерти Учителя», проявляющейся прежде всего в утрате и педагогическим сообществом, и обществом в целом представления о важности выполняемой Учителем социальной миссии.

Ключевые слова: пандемия COVID-19, образование, коммерциализация, воспитание, постмодернизм, «смерть Учителя».

Цитирование. Матвиенко Е. А. Социальные последствия пандемии в контексте проблем современного образования // Logos et Praxis. - 2021. - T. 20, № 2. - C. 74-82. - DOI: https://doi.org/10.15688/lp.jvolsu.2021.2.9

Пандемия COVID-19, обрушившаяся на человечество в конце 2019 г. и продолжающаяся до сих пор, является, очевидно, явлением исторически случайным. Она представляет собой классический пример неожиданной и масштабной катастрофы из числа тех, которые Нассим Талеб в (прославившей его впоследствии) книге предложил именовать «черными лебедями» [Талеб 2020].

Однако, будучи сама по себе роковой случайностью, пандемия оказалась своего рода триггером, давшим старт цепной реакции изменений в самых различных сферах общественной жизни. Эти события имеют собственные глубинные причины, вызревавшие, как правило, в течение длительного времени. Пандемия лишь ускорила наступление (неизбежных?) следствий.

Одной из важнейших областей культуры, где влияние пандемии сказалось особенно сильно, стало образование. Образовательные организации самого различного уровня - от школ до вузов - вынуждены были в массовом порядке переходить на различные формы дистанционного обучения. Но пандемия, повторим, была лишь поводом - хотя и чрезвычайно весомым поводом (!) - к произошедшей на наших глазах трансформации. Причины ее куда глубже и разнообразнее. При этом большинство из них носит универсальный характер (хотя и сдобренный зачастую «национальным колоритом»). Попробуем проанализировать наиболее весомые из указанных причин.

Прежде всего, речь идет об аудиовизуальном повороте в современной культуре. А.Л. Стризое и В.А. Храпова в связи с этим подчеркивают, что если «сравнительно недавно визуализацию как процесс воспроизводства и широкого распространения визуальных образов соотносили с массовой культурой, то в настоящее время эти образы и формируемый ими язык проникают в элитарную культуру, оказывая влияние на репрезентацию культурной классики и творчество в целом» [Стризое, Храпова 2018, 195].

Не меньшее воздействие оказывают они и на образовательную деятельность, радикально влияя на ее технологию, а через последнюю - и на содержательные аспекты образования. «Галактика Гуттенберга» перестала расширяться, более того - она стремительно сжимается. Происходит деградация «книжной культуры» - культуры, по сути, создавшей и поддерживающей здание нашей цивилизации как минимум с эпохи Осевого времени. Значительная часть молодых людей принципиально не хочет в процессе обучения работать с текстом. Хуже того - она просто не в состояние прочитать и понять (а тем более написать!) мало-мальски сложный текст. 
И это - прямое следствие прогрессирующей визуализации усваиваемой информации.

Видеоролики, компьютерные презентации и т. п. технологии обучения, бесспорно, облегчают усвоение учебного материала. Их роль как вспомогательного образовательного инструмента не подвергается сомнению. Проблема, однако, заключается в том, что именно этот инструмент превращается в основной, а нередко и в единственный. Делая материал предельно доступным, такого рода технологии не развивают базовые познавательные способности личности - внимание, память, способность к абстрагированию и анализу. Не формируется и «воля к познанию», стремление и готовность преодолевать возникающие в его ходе неизбежные трудности. Идиома «грызть гранит науки» все менее применима ко дню сегодняшнему, когда обучающиеся хотят получать своего рода «информационное пюре», которое не то что грызть уже и жевать-то не нужно...

Кроме того, очевидно, что визуализировать без грубых искажений можно лишь фактический, иллюстративный материал. Степень абстрактности теории, - будь то физика или философия, - обратно пропорциональна возможности уложить ее в прокрустово ложе (сколь угодно подробной) схемы. Использование подобных технологий неизбежно ведет, таким образом, ко все большему упрощению (в переделе - к примитивизации) учебного материала - что, собственно, и соответствует уровню познавательных способностей обучающихся, одновременно консервируя (в лучшем случае!) этот уровень.

Однако именно вышеназванные педагогические технологии максимально соответствуют дистанционному характеру обучения и активно используются в его ходе. Вынужденный пандемией сверхмасштабный социальный эксперимент показал, что дистанционное (или преимущественно дистанционное) образование как основная его форма технически возможно - если, конечно, оставить в стороне проблему его качества.

Следующий важнейший фактор - тотальная коммерциализация и консьюмеризация образовательной деятельности. Исследователи подчеркивают, что «определяющей тенденцией развития образования в настоящее вре- мя является его ориентация на потребителя» [Николаева, Щелкунов 2009, 12]. Место бескорыстной передачи накопленного цивилизацией опыта занимает оказание возмездной (и, как правило, весьма недешевой) услуги. Однако образование (хотя и обладающее, в том числе, экономической ценностью) - товар весьма специфичный. Т.А. Хагуров отмечает, что в классической интеллектуальной традиции образование представляет собой яркий пример «императивного блага», которое можно заслужить только упорным трудом [Хагуров 2015, 22]. Именно это делает его столь ценным для личности, заставляет испытывать чувство законной гордости («я смог это сделать!»), естественное чувство удовлетворения от хорошо выполненной работы. Купить образование - в отличие от диплома - в общем-то невозможно.

К сожалению, многие обучающиеся, а зачастую и их родители, этот факт до конца не осознают. Отсюда - стремление получить образование минимальными усилиями (в идеале - вообще их не прилагая - ведь за все уже заплачено!). При этом многим кажется, что сам процесс образования должен доставлять школьнику или студенту исключительно удовольствие, быть легким и приятным, с максимальным применением развлекательно-игровых педагогических технологий. Что любопытно, подобные представления все шире распространяются и на те ситуации, где обучение является (по крайней мере, декларативно) бесплатным - например, на общеобразовательную школу. Есть «заказчики» образовательной услуги (дети и родители), а есть «исполнители» (учителя и школьная администрация), услуги которых заказчики опосредовано (чем формируемый ими государственный или муниципальный бюджет) оплачивают.

Поскольку потребитель всегда прав, многие представители родительского сообщества считают возможным ставить перед педагогами разной степени абсурдности требования. В случае же их невыполнения педагог рискует быть обвиненным в разного рода «смертных грехах» - от неуважения к личности ребенка до коррупции. При этом существует своего рода «презумпция вины» учителя, который постоянно находится в положении оправдывающегося. 
Со сходными проблемами, хотя и в меньшей степени, сталкиваются и вузовские педагоги. К тому же средства, получаемые от обучающихся на коммерческой основе студентов составляют важную часть бюджета вуза и, соответственно, зарплаты самого педагога. Для того, чтобы отчислить такого студента, нужны весомые основания зачастую более весомые, чем его хроническая неуспеваемость.

Закономерным следствием превращения образования в услугу нередко становится частичное (а иногда и полное) отсутствие интереса к содержательным аспектам образовательной деятельности как у обучаемых, так и у обучающих. Одни делают вид, что учатся, другие - что учат (тем более что «профессиональная состоятельность» педагога все больше определяется не содержательными аспектами его работы, а ее «описанием» в бурно растущем объеме отчетно-плановой документации). Подлинное образование стремительно вырождается в один из множества бодрийяровских симулякров.

Возможно выше мы несколько сгустили краски. Добросовестных и талантливых студентов пока немало, как и осознающих важность своей социальной миссии преподавателей. Но тенденции, к сожалению, именно таковы. Именно они еще до начала пандемии подталкивали к развитию обучения в дистанционном формате, поскольку данный формат позволяет всем участникам педагогического процесса минимизировать затрачиваемые в его ходе усилия, а государству и вузовской (или школьной) администрации еще и сэкономить значительные материальные ресурсы. Сверхмасштабный социальный эксперимент, вызванный пандемией, показал, что исключительно дистанционное (или преимущественно дистанционное) образование не только вполне возможно технически, но и выгодно экономически - если, конечно, выгоду воспринимать буквально и не задумываться о перспективах.

Третье важнейшее обстоятельство заключается в том, что в последние десятилетия была фактически девальвирована классическая трактовка образования как единства обучения и воспитания. Произошел явный перекос в сторону первого, понимаемого к тому же не столько как процесс усвоения фундаментальных знаний о мире (открывающих путь к его творческому преобразованию), сколько как процесс формирования практических навыков, фактически как дрессура, дающая лишь возможность действовать в строгом соответствии с заданным извне алгоритмом.

Воспитание же, понимаемое как процесс формирования гармонично и всесторонне развитой личности с богатым внутренним миром и четкой ценностной иерархией, в которой высшие позиции занимают стремление творить добро, помогать людям, вносить свой вклад в развитие общества, оказалось на заднем плане, по сути - на задворках образовательного процесса. Так называемые «общекультурные компетенции» оттесняются и вытесняются компетенциями профессиональными, гуманитарный компонент образования все больше деградирует.

При этом адепты узкопрофильного образования активно пользуются известной формулой «хороший человек - это не профессия». С этим трудно спорить. Но очевидно и то, что многих - для большинства (!) - профессий высокий нравственный уровень человека выступает обязательным условием его профессиональной состоятельности. Разумеется, если рассматривать профессиональную деятельность как вклад личности в социальную кооперацию, а не только как средство приобретения материальных благ. Прежде всего, сказанное относится к тем профессиям, представители которых непосредственно работают с людьми - к педагогам, врачам, юристам, чиновникам, сотрудникам полиции и т. д. Только любовь и уважение к людям позволяют понастоящему успешно их учить, лечить, защищать и так далее. Для представителей различных профессий представляется необходимым воспитание и иных личностных качеств [Кобылкин, Доронин, Сухоруков 2017].

Не менее важным результатом воспитания является и «включенность» человека в национальную (а через нее - и в мировую) культуру, становление гражданина и патриота, готового противостоять агрессивной глобализации, осознавать и отстаивать свою идентичность.

Но именно по воспитательному компоненту образования (и так далеко не приори- 
тетному, как было показано) пандемия нанесла очередной чувствительный удар - уже в силу того факта, что проведение значительной части мероприятий воспитательной направленности в дистанционном формате крайне затруднено, а то и вовсе невозможно. Ограниченным оказалось и живое, непосредственное общение как с педагогами, так и с одноклассниками или сокурсниками. Долгое время не представлялось возможным задействовать потенциал учебного коллектива, что также резко снизило эффективность воспитательного воздействия.

Таким образом, инициированный эпидемиологической ситуацией сверхмасштабный социальный эксперимент продемонстрировал, что исключительно дистанционное (или преимущественно дистанционное) образование возможно технически, выгодно экономически и усиливает акцент на прагматический компонент образования (подготовку к будущей профессии) в ущерб компоненту аксиологическому (формирование зрелой, гармонично развитой, ориентированной на служение обществу личности).

Наконец, мощнейшим трендом в развитии образования (как и общества в целом) выступает в последние десятилетия проникновение в него постмодернистских теорий и связанных с ними практик. Позволим себе, по аналогии с широко используемым термином «модернизация», обозначить этот процесс как «постмодернизацию». Истоки его (по крайней мере, применительно к образованию) уходят еще в шестидесятые годы прошлого века. В интеллектуально-идеологическом плане они связаны с (достаточно радикальной) критикой буржуазного общества и лежащих в его основе принципов эпохи Просвещения, предпринятой представителями Франкфуртской школы. Под их влиянием сформировались мощные молодежные и студенческие движения, вдохновлявшиеся причудливым идейным коктейлем из теорий Маркса, Мао и Маркузе, пышным цветом расцвела молодежная контркультура.

Эйфория свободы (точнее, освобождения) подталкивала к разрушению прежних образовательных практик и делала совершенно нетерпимой ситуацию, которую Мишель Фуко назвал «педагогической колонизацией молодежи» [Фуко 2007, с. 86-87]. Ее элемен- тами выступали жесткая пространственно-временная регламентация образовательного пространства и постоянный контроль со стороны облеченного властью и авторитетом наставника. Наряду с больницей, армией и тюрьмой именно школа выступает, по мнению Фуко, классическим образцом новой, дисциплинарной организации власти [Фуко 1999].

Несомненно, оснований для критики прежней образовательной парадигмы было более чем достаточно. Но каковы оказались предлагаемые альтернативы? И. Иллич в приобретшей скандальную известность работе «Общество без школы» выдвигает идею тотальной «десколяризации», заявляя, что образование - личное дело каждого [Illich 1971]. П. Фрейре «педагогике угнетения» противопоставляет «педагогику освобождения». Если первая исходит из идеи «фундаментального неравенства», то вторая целиком строится на диалоге, при котором позиции ученика и учителя «взаимообратимы» [Огурцов, Платонов 2004, 398-402].

Дальше - больше: в 1975 г. выходит работа Э. фон Браунмюля с недвусмысленным названием «Антипедагогика. Очерки к устранению образования». Приведем несколько цитат из нее: воспитание - «более или менее жестокая дрессировка, от которой дети неизбежно заболевают»; «нет педагогики, которая не была бы более или менее явным террором»; «тот, кто хочет воспитывать ребенка, стремится его разрушить» и т. п. [Цит по: Огурцов, Платонов 2004, 409-410]. Не менее откровенно высказывается Г. Шенебек: «Антипедагогика осуществляет слом существующей культуры» (цит. по: [Огурцов, Платонов 2004, 411]).

Указанные и им подобные работы выходят практически одновременно со знаменитым эссе Ж.-Ф. Лиотара «Состояние постмодерна» [Лиотар 1998] и развивают сходные взгляды. В дальнейшем как теоретики, так и практики педагогики активно заимствуют все ключевые идеи философов-постмодернистов. Последние, как известно, яростно атакуют все базовые ценности модерна: разум, истину, науку, свободу. Они стремятся «деконструировать» (а по сути - разрушить) любые устоявшиеся нормы, смыслы и ценности. В сфере теоретической (насколько вообще можно о 
ней говорить применительно к постмодернизму) мы имеем дело с бесчисленными, в принципе не сводимыми к единому знаменателю языковыми играми. С этим коррелируют столь же многообразные жизненные практики, которые больше не рассматриваются в категориях нормы и отклонения от нее - норма всегда есть проявление репрессивного начала, столь типичного для европейской культуры. Любые идеалы подвергаются осмеянию. Осуществляется радикальный разрыв с традицией. При всем своем обостренном внимании к культурно-историческому контексту любого высказывания постмодернисты отказываются признавать наличие в социальном развитии каких-либо причинноследственных связей, выступают с апологией случайности и хаотичности (вспомним метафору ризомы у Жиля Делёза).

На этих же принципах, по мнению посмодернистски ориентированных теоретиков педагогики, должно быть перестроено и образование. Прежде всего, невозможна более универсальная педагогическая теория. Любая такая теория есть разновидность «похороненного» Лиотаром метанарратива. Образование не должно ориентироваться на общезначимые личностные образцы, ибо больше не существует никаких верных ориентиров. Образование не должно (да и не сможет!) приобщать человека к каким-либо истинам и ценностям, ибо и то, и другое относительно. Фигура отца из знаменитого стихотворения Маяковского, рассказывающего крошке-сыну «что такое хорошо и что такое плохо», может быть интерпретирована в постмодернистком духе как олицетворение тоталитарно-репрессивного начала, покушающегося на свободу ребенка рвать книжки и валяться в грязи. Обучающий и обучающийся абсолютно равноправны, последний сам вправе решать, чему и как ему учиться и учиться ли вообще.

На практике все перечисленное очень быстро ведет к катастрофическому падению авторитета педагога и образовательных институтов вообще. Образование все больше превращается из общественной в сугубо частную проблему. При этом главный удар принимает на себя общеобразовательная школа. Нас призывают не перегружать неокрепшую детскую психику «избыточными знаниями», к которым относят практически все, кроме азбуки и четырех действий арифметики. Не выходят из моды разговоры о необходимости «индивидуализации обучения», «персональных образовательных траекториях», «конкуренции смыслов» и т. п. [Карпов 2010]. Едва ли не каждый год меняются образовательные стандарты, содержание программ, рекомендуемые учебники. Любое воспитательное воздействие трактуется как «насилие над личностью ребенка».

Администрация образовательного учреждения зачастую вынуждена заботиться не о том, как обеспечить высокий уровень знаний обучающихся, а о том, как бы ненароком не ущемить права того или иного меньшинства, будь то расовое, гендерное или сексуальное. Так, в ряде школ американского штата Орегон уже перешли к преподаванию «этноматематики», поскольку обычная «утверждает превосходство белой расы» [Рыбин, Приймак web]. Видимо, «на подходе» женская химия и биология для вегетерианцев. Именно постмодернистские теории, будучи инкорпорированы в политическую идеологию, несут изрядную долю ответственности за ту вакханалию толерантности, которая охватила сегодня западную цивилизацию.

Россия последней из указанных тенденций (пока?) до конца не поддается, однако в остальном наблюдается схожая картина. Пандемия оказывается важнейшим фактором ускорения постмодернизации образования. Вследствие дистанционного формата обучения образовательное пространство дробится, атомизируется - как в физическом, так и в интеллектуальном плане. Степень реального участия того или иного школьника/студента в образовательном процессе серьезно варьируется и зачастую не может быть объективно оценена. «Технические проблемы» могут не позволить полноценно работать добросовестным учащимся; для недобросовестных же они превращаются в универсальное оправдание их несобранности и лени. Обучаемые большую часть времени предоставлены самим себе, что и как они изучают - можно установить лишь постфактум (да и то далеко не всегда). «Образовательная траектория» становится воистину индивидуальной, однако ведет она зачастую отнюдь не к знаниям. О воспи- 
тательном же компоненте образования, как уже отмечалось, и вовсе приходится забыть...

Таким образом, финальным пунктом наших рассуждений становится констатация того факта, что запущенный пандемией сверхмасштабный социальный эксперимент наглядно доказал: исключительно дистанционное (или преимущественно дистанционное) образование возможно технически, выгодно экономически, усиливает акцент на прагматический компонент образования в ущерб аксиологическому и способствует прогрессирующей постмодернизации образования, которая выражается во фрагментации образовательного пространства, размывании его универсальных принципов, целей и содержания.

В заключение остановимся еще на одном следствии пандемии. Оно, как и прочие, не порождено пандемией в строгом смысле этого слова, но проявлено и кристаллизовано ею. Это следствие в известном смысле резюмирует все вышесказанное.

Неклассическая западная философия в работах виднейших своих представителей неоднократно обыгрывала метафору смерти той или иной важной «персоны». Ницше (а вслед за ним и другие) констатировал «смерть Бога» [Ницше 1993]. Мишель Фуко заявил о «смерти субъекта» [Фуко 1977]. Ролан Барт, конкретизируя последний тезис, писал о «смерти автора» [Барт 1989].

На наш взгляд, пандемия окончательно привела к «смерти Учителя». Его болезнь была тяжелой и продолжительной. Симптомы удачно описаны 3. Бауманом. Философ указывает, что мир больше не нуждается в авторитетах, лидерах и учителях [Бауман 2008, 7172]. Никто больше не выступает глашатаем истины, не вдохновляет (в том числе личным примером), не ведет за собой. Место Учителей занимают разнообразные консультанты. Последние не выполняют важную для общества и истории миссию, но лишь оказывают услугу - соответственно, вполне могут быть «уволены» недовольным «клиентом». В образовательный процесс активно включается фигура «тьютора», который лишь помогает обучающемуся сделать выбор и не претендует на нечто большее.

Извращается изначально здравая идея диалогичности образовательного процесса, постулируется абсолютное равенство учителя и ученика. Типичным (для европейских школ) становится обращение к учителю на «ты» и по имени. Авторитет педагога стремительно падает. В нашей стране ускоряющими этот процесс факторами выступают более чем скромное вознаграждение нелегкого преподавательского труда и бессилие педагога перед бюрократическим абсурдом и произволом; на Западе - необходимость безусловно следовать жестким требованиям политкорректности и позитивной дискриминации.

Пандемия добавила к этому фактическую утрату непосредственного контакта ученика и учителя. Такой контакт позволял лучшим представителям педагогического сообщества засчет личных и профессиональных качеств нивелировать негативное влияние вышеперечисленных объективных факторов. В условиях «цифровизации» образования этот ресурс больше не может быть задействован.

В частности, А.А. Остапенко обращает внимание на то, что основанный на жестких технологических схемах дистанционный формат образования наносит удар «по трем важнейшим признакам педагогики как искусства, по трем важнейшим “и”: интуиция, импровизация и интонация» [Остапенко 2019, 38-39]. Эти компоненты, как и многие другие,педагогического мастерства в принципе не поддаются оцифровке. Крайне затрудняется вовлечение в активную работу на занятии основной массы обучающихся, ведущих себя, как правило, достаточно пассивно. «Раскачать» эту инертную, но потенциально способную на большее, массу, работая в дистанционном формате, практически невозможно [Доронин 2015, 131].

Самое печальное заключается, однако, в том, что и сами педагоги в массе своей все более разочаровываются в своей миссии, миссии, о важности которой много и красиво говорят, но в выполнении которой мало желающих помочь. В полном соответствии с духом эпохи учитель привыкает относиться к ученику как к обезличенному «предмету труда» (чему как нельзя более способствует дистанционное обучение), а к своей профессиональной деятельности - исключительно как к способу получения средств к существованию («работа как работа...»). Он считает себя 
обязанным лишь выполнить определенный комплекс стандартных действий, результат которых никому, по большому счету, не интересен, а в условиях пандемии - и не вполне зависит от педагога. Общество больше не ценит труд Учителя и последний отвечает ему взаимностью.

Является ли «смерть Учителя» лишь «клинической» и, стало быть, придающей смысл реанимационным мероприятиям? Или же это смерть «биологическая», окончательная и бесповоротная? Решение этих вопросов должно, на наш взгляд, стать основным содержанием постпандемической философии образования.

\section{СПИСОК ЛИТЕРАТУРЫ}

Барт 1989 - Барт Р. Смерть автора // Избранные работы: Семиотика. Поэтика. М.: Прогресс, 1989.

Бауман 2008 - Бауман 3. Текучая современность. СПб.: Питер, 2008.

Доронин 2015 - Доронин Ю.П. Индивидуальное контрольное собеседование - одна из форм учебного процесса в образовательной организации МВД России // Вестник Волгоградской академии МВД России. 2015. № 1 (32). C. $130-134$

Карпов 2010 - Карпов А.О. Образовательная эпистемология постмодернизма // Философия образования. 2010. № 1 (30). С. 113-121.

Кобылкин, Доронин, Сухоруков 2017 - Кобылкин Р.А., Доронин Ю.П., Сухоруков В.А. Патриотическое воспитание сотрудников ОВД в контексте отечественной истории // Вестник Волгоградской академии МВД России. 2017. № 4 (43). C. $143-147$.

Лиотар 1998 - Лиотар Ж.-Ф. Состояние постмодерна. СПб.: Алетейя, 1998.

Николаева, Щелкунов 2009 - Николаева E.M., Щелкунов М.Д. Образование в обществе потребления // Философия образования. 2009. № 1 (26). C. 11-19.

Ницше 1993 - Ницше Ф. Веселая наука // Избранные произведения. М.: Просвещение, 1993.

Огурцов, Платонов 2004-Осуричов А.П., Платонов В.В. Образы образования. Западная философия образования. ХХ век. СПб.: РХГИ, 2004.

Остапенко 2019 - Остапенко A.A. Можно ли оцифровать педагогическое мастерство? // Цифровизация и молодежь. Материалы научнопрактической конференции. М.: Фонд «Просветитель», 2019. С. 38-46.
Рыбин, Приймак web - Рыбин А., Приймак А. Что такое этноматематика»? [Взгляд. Деловая газета. 25.02.2021]// https://vz.ru/question/2021/ 2/25/1086659.html.

Стризое, Храпова 2018 - Стризое А.Л., Храпова В.А. Вербальное и визуальное в культуре: иерархия или дополнительность? // Вопросы философии. 2018. № 6. С. 194-199.

Талеб 2020 - Талеб Н. Черный лебедь: под знаком непредсказуемости. М.: КоЛибри, 2020.

Фуко 1977 - Фуко М. Слова и вещи: археология гуманитарных наук. М.: Прогресс, 1977.

Фуко 1999 - Фуко М. Надзирать и наказывать: рождение тюрьмы. М.: Ad Marginem, 1999.

Фуко 2007 - Фуко М. Психиатрическая власть. СПб.: Наука, 2007.

Хагуров 2015 - Хагуров Т.А. На краю пропасти. Девиантологические этюды об образовании, культуре и политике. Краснодар: Парабеллум, 2015.

Illich 1971 -Illich I. Deschooling Society. N. Y.: Harrow Books, 1971.

\section{REFERENCES}

Barthes R., 1989. Death of the Author. Selected Works: Semiotics. Poetics. Moscow, Progress Publ.

Bauman Z., 2008. Liquid Modernity. St. Petersburg, Piter Publ.

Doronin Yu.P., 2015. Personal Control Interview as One of the Forms of the Educational Process in the Educational Organization of the Ministry of Internal Affairs of Russia. Vestnik Volgogradskoy akademii MVD Rossii, no. 1 (32), pp. 130-134.

Karpov A.O., 2010. Educational Epistemology of Postmodernism. Filosophia obrazovaniya, no. 1 (30), pp. 113-121.

Kobylkin R.A., Doronin Y.P., Sukhorukov V.A., 2017. Patriotic Upbringing of Police Officers in the Context of Russian History. Vestnik Volgogradskoy akademii MVD Rossii, no. 4 (43), pp. 143-147.

Lyotard J.-F., 1998. The State of Postmodernity. Saint Petersburg, Aleteya Publ.

Nikolaeva E.M., Shelkunov M.D., 2009. Education in the Consumer Society. Filosophia obrazovaniya, no. 1 (26), pp. 11-19.

Nietzsche F., 1993. Fun Science. Selected Works. Moscow, Prosveshenie Publ.

Ogurtsov A.P., Platonov V.V., 2004. Images of Education. Western Philosophy of Education. $X X$ Century. Saint Petersburg, RHGI.

Ostapenko A.A., 2019. Is it Possible to Digitize Teaching Skills? Tsifrovizatsiya i molodezh. Papers of the Scientific and Practical Conference. Moscow, Fond «Prosvetitel», pp. 38-46. 
Rybin A., Priymak A. What is "Ethnomathematics"? Vzgliad. Delovaya Gazeta. 25.02.2021. URL: https://vz.ru/question/2021/2/25/1086659.html

Strizoe A.L., Khrapova V.A., 2018. Verbal and Visual in Culture: Hierarchy or Complementarity? Voprosy filosofii, no. 6, pp. 194-199.

Taleb N., 2020. The Black Swan: The Impact of the Highly Improbable. Moscow, KoLibri Publ.

Foucault M., 1977. Words and Things: the Archaeology of the Humanities. Moscow, Progress Publ.
Foucault M., 1999. Overseeing and Punishing: The Birth of Prison. Moscow, Ad Marginem Publ.

Foucault M., 2007. Psychiatric Authority. St. Petersburg, Nauka Publ.

Khagurov T.A., 2015. On the Edge of the Abyss. Deviantological Studies in Education, Culture and Politics. Krasnodar, Parabellum Publ.

Illich I., 1971. Deschooling Society. New York, Harrow Books Publ.

\section{Information About the Author}

Evgeniy A. Matvienko, Candidate of Sciences (Philosophy), Associate Professor, Chief of the Department of Philosophy of the Volgograd Academy of Ministry of Internal Affairs of Russia, Istoricheskaya St, 130, 400089 Volgograd, Russian Federation; Master Student, Department of Philosophy, Volgograd State University, Prosp. Universitetsky, 100, 400062 Volgograd, Russian Federation, matvment@mail.ru, https://orcid.org/0000-0001-6921-1509

\section{Информация об авторе}

Евгений Алексеевич Матвиенко, кандидат философских наук, доцент, начальник кафедры философии, Волгоградская академия МВД России, ул. Историческая, 130, 400089 г. Волгоград, Российская Федерация; магистрант кафедры философии, Волгоградский государственный университет, просп. Университетский, 100, 400062 г. Волгоград, Российская Федерация, matvment@mail.ru, https://orcid.org/0000-0001-6921-1509 